\title{
LA MALDICIÓN DE LOS LABDÁCIDAS EN LA ÓPERA DE LOS SIGLOS XX Y XXI
}

\author{
Ronald Forero \\ Universidad de la Sabana. Colombia \\ Lucio Martín Forero Álvarez \\ Universidad Autónoma de Colombia
}

Resumen: En los siglos XX y XXI, Stravinski (Oedipus Rex, 1927), Enescu (Oedipe, 1936), Orff (Antigone, 1949; Oedipus der Tyrann, 1959), Turnage

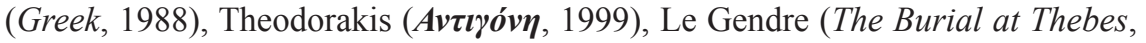
2008), Anderson (Thebans, 2014), entre otros, compusieron óperas sobre el mito de los labdácidas. Un hecho bastante significativo si tenemos en cuenta que durante el Romanticismo contamos con apenas dos dramas musicales de Mendelssohn relacionados con los personajes del Ciclo Tebano (Antigone, 1841 y Oedipusauf Kolonos, 1845). El objetivo, por tanto, de este estudio es analizar las óperas sobre este mito compuestas desde 1901 con el fin de comprender su resurgimiento en el contexto operístico contemporáneo.

Palabras clave: Mito, Labdácidas, Ciclo tebano, Ópera, Edipo, Antígona

\section{THE CURSE OF LABDACIDS IN THE $20^{\mathrm{TH}}$ AND $21^{\mathrm{TH}}$ CENTURIES OPERA}

\begin{abstract}
In the $20^{\text {th }}$ and $21^{\text {th }}$ centuries, Stravinsky (Oedipus Rex, 1927), Enescu (Oedipe, 1936), Orff (Antigone, 1949; Oedipus der Tyrann, 1959), Turnage

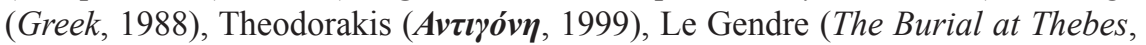
2008), and Anderson (Thebans, 2014), among others, composed operas about the myth of Labdacids. A fact quite significant if it is taken into account that during Romanticism there are just two musical dramas by Mendelssohn related to characters of the Theban Cycle (Antigone, 1841 and Oedipus auf Kolonos, 1845). The aim of this article, therefore, is to analyse the operas about this myth composed since 1901 in order to understand its resurgence in the contemporary operatic context.
\end{abstract}

Keywords: Myth, Labdacids, Theban Cycle, Opera, Oedipus, Antigone

Recibido: 12.09.2017 - Aceptado: 2.11.2017 
Correspondencia: Ronald Forero Alvarez

Email: ronal.forero@unisabana.edu.co

Profesor Universidad de la Sabana. Colombia. Doctor en Textos de la

Antigüedad Clásica y su Pervivencia, Universidad de Salamanca.

Correspondencia: Lucio Martín Forero Álvarez

Email: luciomart89@gmail.com

Historiador con énfasis en Patrimonio histórico y Museología,

Universidad Autónoma de Colombia

T os mitos griegos y romanos han sido una fuente inagotable de inspiración para la producción musical occidental. Ya desde la antigüedadencontramos quelos dramaturgos tomaron de la tradición mitológica argumentos para componer obras en las que conjugaban poesía, música, danza y escenografía.Varios siglos más tarde, durante el Renacimiento, se compusieron dramas pastorales, madrigales e intermedios basados en mitos grecorromanos, así como propuestas de interpretación para la tragedia griega y romana,debido a que no había un consenso entorno al papel de la música en los dramas antiguos. Dichas composiciones aportaronlos elementos necesarios para la consolidación y desarrollo del género operístico en el siglo XVII. Desde entonces, la ópera siguió ganandoimportancia en Occidente y se convirtió en un escenario prominente de divulgación cultural, en el que la recreación de los mitos antiguos y la recepción de las culturas clásicas tuvieron un espacio sustancial. En este ámbito artístico, el mito de los labdácidas ha tenido un particular tratamiento, ya que en la Antigüedad Clásica se compusieron un gran número de tragedias, cuyo argumento estaba basado en personajes de este mito. Infortunadamente, solo un puñado de aquellas obras se ha transmitido completo; de otras, solo se conservanfragmentos o referencias a sus títulos y contenidos ${ }^{1}$.

Durante el Renacimiento, resulta de especial interés la composición

1 De la literatura griega, tenemos noticias de las siguientes tragedias: la trilogía Edipo, Layo y Los Siete contra Tebas de Esquilo; Las Fenicias de Frínico; Edipo Rey, Edipo en Colono y Antígona de Sófocles; LasFenicias de Eurípides; y Edipo de Diógenes de Sinope. También se encuentran referencias en la Comedia Nueva de dos obras de Alexis tituladas Los Siete contra Tebas y Los Tebanos. En la literatura romana, encontramos las siguientes: Tebas, Fenicias, Antígona, 
Oedipus Rex (1585)de Andrea Gabrieli (c. 1510-1586), una de las primeras propuestas sobre la interpretación de la tragedia antigua, tras décadas de teorización en torno a los contenidos de la Poética de Aristóteles dedicados a la tragedia (Clubb, 2001, p.123). Para Gabrieli únicamente los coros eran cantados, por lo que, para su representación de la tragedia en el Teatro Olímpico de Vicenza, compuso música únicamente para las partes corales, con textos de la traducción en verso de la obra de Sófocles de Lionardo Giustiniani (Fenlon, 2008, p.128)2.

En el Barroco, el mito de los labdácidas siguió inspirando composiciones operísticas, todas ellas basadas en las tragedias de Sófocles. Sobre todo en el ámbito italiano, pues a excepción del Oedipus (1751, Rudolstadt) del compositor alemán Georg Gebel Jr. (1709-1753), libreto de J. G. Kloss, las otras cinco son de compositores italianos ${ }^{3}$.

Los compositores del clasicismo, por su parte, en su gran mayoría italianos, mostraron una gran atracción por la figura de Antígona, ya que tan solo cuatro de las veintidós composiciones que se registran de este período están dedicadas a Edipo y a Creonte, todas ellas basadas en Edipo en Colono y en Antígona 4 .

Epígonos, Erifila, Alcimeo y Alfesibea de Acio; Edipo de Julio César; Edipo Rey y Las Fenicias de Séneca; y La Tebaida de Estacio.

2 En 1615, Leone Leoni (c. 1560-1627) presentó su propia propuesta interpretativa de la tragedia de Edipo (Bettini \& Guidorizzi, 2008, p.186). No se conserva la música compuesta para dicha representación, pero con toda probabilidad seguía el modelo de los coros del Edipo de Gabrieli (Bosi, 2003, p.85).

3 Estas son, a saber: Creonte (1690, Venecia) de Marc' Antonio Ziani (c.16531715), libreto de Rinaldo Cialli; L'Antigona (1717, Venecia) de Antonio Maria Lucchini (fl.1716-1730), libreto del mismo Lucchini; Antigona (1718, Venecia) de Giuseppe Maria Orlandini (1676-1760), libreto de Benedetto Pasqualigo; Edippo (1729, Múnich) de Pietro Torri (c.1650-1737), libreto de Domenico Lalli; y Antigone (1751, Roma) de Baldassare Galuppi (1706-1785), libreto de Gaetano Roccaforte. Este último libreto tuvo numerosas representaciones y adaptaciones en el clasicismo, como puede verse en la nota siguiente. En la versión de Roccaforte Antígona no se suicida, sino que huye y se enfrenta a toda suerte de peripecias, dando como resultado una continuación de la tragedia de Sófocles 'vivacemente romanzata', en palabras de Mechelli (2011, p.79).

4 Estas son con libreto de Gaetano Roccaforte: Antigona (1752, Florencia) de Michele Fini; Antigona (1752, Turín) de Giovanni Battista Casali (c.1715- 
Durante el Romanticismo, por el contrario, los compositores de ópera no mostraron interésen los personajes del Ciclo Tebano, salvo por dos composiciones de corte operístico del compositor alemán Felix Mendelssohn Bartholdy (1809-1847). Se trata de dos dramas musicales: Antigone op. 55, MWV M 12 (1841, Potsdam) y Oedipus auf Kolonos op. 93, MWV M 14 (1845, Potsdam).

En el caso de los compositores del siglo XX tenemos noticias de diecinueve composiciones operísticasy,en lo que va del presente siglo, deseis. Tal registro indica un resurgimiento y una revaloración del mito del Ciclo Tebanocomomedio de expresión artística.De modo que indagar y reflexionar sobre este fenómeno resulta de interés, ya que el referente mitológico es adaptado en cada obra según los intereses estéticos, artísticos e ideológicos de cada compositor. El objetivo, por tanto, de este artículo es analizar las óperas que tienen como protagonista a alguno de los personajes del mito de los labdácidasdesde 1901, haciendo énfasis en los aspectos más sobresalientes de cada una.

La primera ópera representada en el siglo XX, relacionada con los labdácidas, es Edipo Re (1920, Chicago) del compositor italiano Ruggero Leoncavallo (1857-1919). Aunque el estreno fue un año después de

1792); Antigona (1753, Módena) de Gaetano Latilla (1711-1788); Antigona (1756, Génova) de Ferdinando Bertoni (1725-1813); Antigona (1756, Milán) de Giuseppe Scarlatti (?1718-1777); Antigona (1760, Londres) de Gioacchino Cocchi (c.1720-1788); Antigona (1762, Venecia) de Vincenzo Ciampi (?17191762); L'Antigona in Tebe (1767, Padua) de Pompeo Sales (c.1729-1797); Antigona (1768, Roma) de Gian Francesco de Majo (1732-1770); Antigona (1774, Turín) del compositor checo Josef Mysliveček (1737-1781); Antigona (1776, Venecia) de Michele Mortellari (c.1750-1807); Antigona (1781, Nápoles) de Giuseppe Gazzaniga (1743-1818). Con libreto de Marco Coltellini: Antigona (1772, San Petersburgo) de Marco Coltellini (1719-1777); Antigona (1789, Milán) de Vincenzo Campobasso d'Alessandro (1760-1788); Antigona (1791, Nápoles) de Peter Winter (1754-1825). Con textos de otros libretistas:Antigone (1790, París) de Niccolò Zingarelli (1752-1837), libreto de Jean François Marmontel; Antigona (1796, Londres) de Francesco Bianchi (1752-1810), libreto de Lorenzo da Ponte; Antigona (1799, Venecia) de Francesco Basili (1767-1850), libreto de Gaetano Rossi.

5 El texto de Antígona es la traducción de Johann Jakob Christian Donner. Para los episodios de Oedipus auf Kolonos, el compositor eligió la versión de Erich Fritze; para las partes corales, la versión de Donner (Flashar, 1991, pp.80-1). 
su muerte, el compositor había contemplado, ya desde finales del siglo anterior, la idea de una composición con temática clásica (Beta, 2002, p.33). La obra se enmarca en la escuela verista de finales del siglo XIX, de la cual Leoncavallo era uno de los principales representantes. Es notable que el compositor haya recurrido a este mito, ya que los postulados del Verismo planteaban que los personajes de los dramas debían reflejarsituaciones y emociones reales. Muestra de ello son sus famosas óperas I Pagliacci (1892) y La Bohème (1897). No obstante, el Edipo de Leoncavallo tiene una dimensión patética distinta, que se aleja del carácter arrogante e irascible del Edipo de Sófocles, aunque el libreto de Giovacchino Forzano lo tenga como referente (Beta, 2002, pp.52-3).

La primera obra propiamente concebida y compuesta durante el siglo XX es la ópera-oratorio Oedipus Rex (1927, París) del compositor ruso Ígor Stravinski (1882-1971). Esta obra, enmarcada en el Neoclasicismo, revela un cambio en las influencias musicales de su Rusia natal y muestra una tendencia hacia las obras escénicas heredadas de la tradición europea (Walsh, 1993, p.103). También manifiesta el deseo de los compositores neoclásicos de volver al orden, luego del caos y la devastación producidos por la Primera Guerra Mundial. Es por esto que la obra es un referente importantísimo en este sentido, pues Stravinski establece un paralelo entre su estilo musical y la elección de un escenario análogo: una ciudad que ha sido sitiada y arrasada varias veces y que busca desesperadamente escapar de la miseria. Es, por tanto, la puesta en escena de este mito una profunda reflexión sobre la realidad circundante, no solo en la obra del compositor ruso, sino también en las demás, como veremos más adelante. Por otra parte, la elección de Stravinski de la lengua latina para el libreto se debió a que el compositor quería desligar la música del texto para darle solemnidad y lograr mayor preponderancia en los aspectos musicales. Asimismo, la inclusión de un narrador en una lengua vernácula, que va recordando la trama del mito, permite a la obra apartarse de un referente lingüístico específico, proporcionándole de esta manera un carácter universal. El libreto estuvo a cargo de Jean Cocteau, quien resumió la obra de Sófocles teniendo en cuenta los aspectos escénicos y los puntos de mayor dramatismo. Por el determinante papel de Stravisnki en la música occidental, es la obra más conocida y más influyente sobre el tema edípico y un referente ineludible para los compositores posteriores, no solo en el tratamiento del mito, sino también en los aspectos musicales. 
A finales del mismo año, el compositor suizo Arthur Honegger (1892-1955), quien desarrolló su actividad musical principalmente en Francia, estrenó su obra Antigone (Bruselas, 1927). El libreto fue una adaptación de la versión de Jean Cocteau de la Antígona de Sófocles. La versión de Cocteau había sido estrenada en 1922 en el Théâtre de l'Atelier con música incidental de Honegger, por encargo de Charles Dullin; la escenografía estuvo a cargo de Pablo Picasso y el vestuario por parte de Coco Chanel. La versión de la tragedia griega está aquí astutamente abreviada, tal como lo hizo Cocteau con su versión de Oedipus Rex, para proporcionarle una perspectiva moderna, que hace énfasis en los dilemas morales. Esta interpretación o apropiación, en opinión de Fulcher (2006, p.658), resultó de la rebeldía de la juventud francesa ante la sociedad conservadora y patriótica, durante la guerra y después de ella. La primera representación de la ópera recibió un rechazo por parte del público, debido al contenido, la complejidad y las innovaciones musicales. No obstante, en el estreno parisino de 1943, la obra fue elogiada y considerada como una pieza maestra. Esta recepción ambivalente se dio porque el compositor combinó los estilos tonal y atonal para su ópera, dentro de una mezcla de influencias musicales francesas y alemanas. Por otra parte, el estreno parisino se realizó en el marco de la Segunda Guerra Mundial, cuando el estado francés dominado por la Alemania Nazi instauró el régimen de Vichy presidido por Philippe Pétain.Sus políticas sociales y culturales debían estar ligadas con la Tercera República, aunque se vio permeada por discusiones en torno al nacionalismo, la tradición, el orgullo francés y la influencia alemana en la cultura francesa, sin dejar a un lado las discusiones sobre temas raciales y políticos (Fulcher, 2006, p.654). En este contexto, la Antígona de Honegger atizó estas discusiones, puesto que parecía enmarcarse entre ambas influencias.

El compositor rumano George Enescu (1881-1955) estrenó su ópera Oedipe, en 1936 (París).Si bien la concepción de la obra data de 1910, la labor de composición fue interrumpida debido al estallido de la Primera Guerra Mundial. En 1921 volvió a su proyecto inicial, haciendo una versión reducida para piano. Finalmente, en 1931, hace la versión completa para orquesta. En su ópera se vislumbra la influencia de Claude Debussy (1862-1918) y de su maestro Gabriel Fauré (1845-1924), por lo que su obra tiene un estilo neoclásico mezclado con un impresionismo 
heterodoxo ${ }^{6}$. El libreto de Edmond Fleg se basa en la conjunción de las tres tragedias de Sófocles que dedica al Ciclo tebano; la obra respeta el orden cronológico de la historia, acogiendo todas las etapas de vida de Edipo desde su nacimiento hasta su muerte (Cotello, 2001).

De la posguerra son dos óperas del compositor alemán Carl Orff (1895-1982): la primera es Antigonae (Salzburgo) estrenada en 1949 y la segunda, Oedipus der Tyrann (Stuttgart), estrenada una década después. Ambas obras comparten características en tanto que Orff consideraba que la tragedia griega era un género musical como tal y que debía ser rescatado. Partió para ello de la ópera de finales del siglo XVI, que según él revivía el drama clásico;por tal razón, en la década de 1920 adaptó libremente la Fábula de Orfeo de Monteverdi (Kaminski, 2003). El compositor recrea sus obras a partir de la corporeidad sensible y la presencia ritual de la palabra trágica en el teatro musical. Su estilo único y poco ortodoxo no tiene paralelo, aunque parte del Neoclasicismo, pues da importancia al lenguaje musical trágico, reproduciendo el texto de manera gestual, con fases cortas y dando profundidad a las emociones de la figura trágica. Orff toma como libreto la traducción de Hölderlin para las dos tragedias de manera íntegra ${ }^{7}$. Las voces traducen las notas musicales en sílabas. Los arreglos orquestales se reducen a una instrumentación que está conformada básicamente por instrumentos de percusión, cuatro a seis pianos y algunos instrumentos de viento (Werner, 1991).

6 Francisco Camino comenta la capacidad interpretativa del personaje de Edipo diciendo lo siguiente: "En Edipo se explota meticulosamente todo tipo de recursos vocales, hilándose el discurso a través de un recitativo que nos retrotrae hasta Monteverdi" (Camino, p.153).

7 Las traducciones de Hölderlin no tuvieron una recepción positiva entre sus contemporáneos, hasta tal punto que Hegel desaconsejó incluirlas en la edición de sus poemas. Solo hasta el siglo XX, tal como comenta Oyarzún (2001, p.80), fueron apreciadas en la radicalidad de su propuesta, que consistía en una flexibilidad de la sintaxis que se alejaba del alemán estándar en favor de una mayor literalidad con respecto al original griego (Bernofsky, 2001, p.220). Por otra parte, de acuerdo con Uscatescu (1980, pp.45-46), Hölderlin descubre la culminación de la obra de Sófocles en la perfección artística de Edipo, una obra moderna, en cuanto se mantiene vigente a través del tiempo; y en el carácter excepcional de Antígona, en la que se encuentra la síntesis suprema de la tragedia griega. 
Siguiendo la línea del Neoclasicismo, el compositor norteamericano Harry Partch (1901-1974) compuso y modificó en varias ocasiones su ópera Oedipus, que finalmente se llamaría The King Oedipus, estrenada en el Mills College, Oakland, California, en 1952.Su trabajo, que se enmarca en la misma concepción teórica de Orff, consiste en revivir y proponer una nueva interpretación de la tragedia griega en la ópera. Por tal motivo, hace una búsqueda de los sistemas tonales de los primeros teóricos musicales, como Pitágoras. Esto lo llevó a utilizar los antiguos sistemas griegos de afinación y sistemas musicales poco usuales, así como ala elaboración de nuevos instrumentos, que lo condujeron a yuxtaponer diferentes estilos musicales en la composición de la obra. Sin embargo, la idea de Partch de hacer una composición que tuviera una homogeneidad discursiva y musical, terminó por generar aplazamientos en el proyecto. Partch expone la saturación emocional y trascendental a través de los diálogos. El coro de mujeres tiene un tono de lamentación; las interpretaciones de los instrumentos y las danzas recrean un ambiente de oscuridad y tensión, con el que Partch logra una atmósfera trágica (Blackburn, 1998). El libreto es la traducción del Edipo Rey de Sófocles del poeta y dramaturgo irlandés William Yeats. Se trata de una reelaboración de la traducción de Sir Richard Jebb, que tenía como propósito la producción de un texto adecuado para ser cantado o hablado, sin tener en cuenta las posibles críticas de los eruditos o de otro tipo de lectores acostumbrados a traducciones más literales o poéticas. De manera que, en esta versión, se evitan las palabras alejadas del lenguaje hablado o frases en un orden distinto al común que frenen la emoción y mengüen la atención ${ }^{8}$. También se omiten ciertas líneas o pasajes que Yeats no consideraba esenciales, en favor de un desarrollo más rápido del tempo y una mejor adecuación al teatro moderno (Grab, 1972, pp.343ss).

La primera ópera del siglo XX que hace referencia a un suceso histórico concreto es Antigona '43 (Rousse) estrenada en el Sofia Music School, en 1963, del compositor búlgaro Lyubomir Pipkov (1904-1974). La óperase enmarca en el contexto de la lucha antifascista durante la Segunda Guerra Mundial. El libreto fue escrito por Vladimir Bashevy Pancho Panchev, basado en la tragedia de Sófocles (Brown, 2004, p.307). Con su ópera, Pipkov busca hacer reflexiones filosóficas y éticas sobre las situaciones humanas vividas durante la guerra. La obra está compuesta

8 Cfr. Yeats (1928, p.v). 
en un estilo recitativo en el que el coro hace las veces de comentarista. $\mathrm{Su}$ estilo, influido por Mussorgski, reinterpreta la esencia de la canción popular en un lenguaje contemporáneo, en el que trata de resolver la dicotomía entre el texto y la música (Richter, 2005).

La siguiente obra, poco conocida, es The passion of Oedipus (1968, Los Ángeles), ópera en dos actos compuesta por el compositor estadunidense Roy Travis (1922). El libreto fue una adaptación libre del propio compositor a partir del Edipo Rey de Sófocles. En esta adaptación de la tragedia, la solución del enigma de la esfinge y asesinato involuntario de Layo por su propio hijo son revelados al público en una serie de escenas retrospectivas, en las que el coro tiene un papel activo en el desarrollo de la trama. El estilo musical es principalmente tonal, pero incluye pasajes harmónicos (Ross Griffel, 2013, pp.367-8).

Pocos años más tarde en 1973, el compositor estadunidense Meyer Kupferman (1926-2003) estrenó Antigonae (1973, Stockbridge). Como la anterior, poca información ha podido recabarse.Se trata de un ópera en un acto para soprano y orquesta de cámara (Kupferman, 2010), basada en la traducción de Hölderlin de la tragedia de Sófocles (Brown, 2004, p.308).

La década de 1970 inicia con la representación de The Death of Antigone (1971, Oxford) de compositor inglés Reginald Smith Brindle (1917-2003). Como en el caso de las dos anteriores la información es escasa. Es una mini ópera para mezzo-soprano, voces graves y una reducida orquesta de cámara. Los pictogramas instrumentales mostrados son enteramente consistentes con aquellos usados por Smith Brindle en otros trabajos de percusión (Read, 1998, p.121). El libreto fue escrito por el compositor a partir de Sófocles y Eurípides (Ross Griffel, 2013, p.116).

De la década de 1980data la obra del compositor catalán Josep Soler i Sardà (1935) Oedipus et Iocasta, estrenada en 1986 (Barcelona) . La obra está relacionada con el profundo estudio del compositor sobre los clásicos y la musicología. Particularmente, sobre la tragedia, que aborda con su interpretación de Séneca, haciendo énfasis en la predestinación de los personajes y su incapacidad de superar su destino, a partir de las herramientas que les proporciona su condición humana. El libreto sigue la versión de Séneca, con interpolaciones de algunos versos de Las Fenicias de Séneca y del Edipo Rey de Sófocles. Por un lado, estas modificaciones del texto se debieron a que el compositor deseaba que el papel de Yocasta

9 Interpretada en 1974 como oratorio en el Palau de la Música Catalana. 
tuviera más peso en el drama, ya que en la versión del filósofo estoico la relación materno-filial y el incesto no están en un primer plano (Bruach Menchén, 2010). Por otro lado, la conclusión que realizó Séneca sobre el conflicto en el desenlace de la tragedia tiene que ver con un problema teológico, ignorando una dimensión humana. Así, la ópera de Soler se basa en el mito en cuanto la divinidad se ve reflejada en un personaje físicamente ausente, pero con una omnipresencia espiritual a partir de los acontecimientos que se adivinan "y que de alguna manera se encontrarán inscritos en la presciencia trascendente, prácticamente como cruel y despiadada coautora de la tragedia que replantea, así en clave artística, el tema de la culpabilidad divina frente a la miseria humana" (Bruach Menchén, 2010, p.127). La música de la obra tiene influencia wagneriana y se aleja de la técnica serial de sus obras anteriores.

La ópera Greek (1988, Múnich) de Mark-Anthony Turnage (1960), tal vez el más exitoso compositor de la 'Nueva Música', es una reelaboración del mito de Edipo. El libreto del compositor y Jonathan Moore es una reelaboración de la obra de teatro homónima de Steven Berkoff. La trama se sitúa en el extremo este de Londres a finales del siglo XX. El argumento, de acuerdo con Ross Griffel (2013, p.206-7), es como sigue: El protagonista, Eddy, que proviene de una familia de clase obrera, entra en el mundo de la libre empresa, pero es incapaz de adaptarse al sistema. En medio de una discusión trivial termina por matar al administrador de un café y se casa con su esposa. Se gana finalmente el respeto y hace las paces con sus padres. Para terminar la plaga de codicia y egoísmo que gobierna su país, Eddy resuelve el enigma de dos lesbianas que protegen la 'Esfinge' a las afueras de la ciudad. Regresa triunfante, únicamente para enterarse de boca de sus padres que él fue adoptado durante la guerra y que su esposa es también su madre. La adaptación del mito en esta ópera destaca por su habilidad en crear una disyunción irónica entre las resonancias de una visión idealizada del mito clásico y su propia reubicación de la historia(Ewans, 2007, p.185). En efecto, el mito es transformado para poner en evidencia las conductas que azotan como una plaga la sociedad actual.

Otra obra que hace una referencia directa a hechoshistóricos es la Antígona furiosa (1991, Múnich) del compositor estadunidense de origen argentino Jorge Mario Liderman (1957-2008). Es una adaptación de la versión de Antígona de la dramaturga argentina Griselda Gambaro, por encargo del compositor alemán Hans Werner Henze (Dana, 2017). El libreto estuvo a cargo de Adriana Feder. La versión de Gambaro utiliza a Antígona 
para mostrar el contexto sociopolítico argentino durante la dictadura de Jorge Rafael Videla (1976-1983), sin dejar de lado el contexto original de la tragedia.La historia se sitúa en la Argentina de los años setenta, cuando miles de mujeres, conocidas como las Madres de los Desaparecidos, se congregaron para manifestarse en contra del autodenominado Proceso de Reorganización Nacional, quesecuestró, torturó y mató a sus esposos e hijos. Dichas víctimas siguieron reclamando al gobierno,después de la dictadura, el esclarecimiento de la verdad sobre las muertes de sus seres queridos.Los sectores conservadores de la política argentina, por su parte, rechazaban estas manifestaciones considerando que estaban trastornadas mentalmente por recordar a sus muertos. La obra solo tiene tres personajes que se desdoblan a lo largo de la historia: Antígona le da voz a Hemón y a Ismene, Corifeo representa la personalidad de Creonte y Antínoo hace de coro (Gidi Blanchet, 2016). El compositor utiliza en su obra elementos de música tradicional argentina y judía, con patente influencia de Stravisnki y Bartok.

En esta misma década, el compositor holandés Ton de Leeuw (1926-1996) recrea, en el estreno de 1993, otra Antigone (Ámsterdam).El libreto es del propio compositor, basado en Sófocles, en el que aborda el drama humano ysobrehumano como espectáculo sacro. El drama humano es representado por Antígona y Creonte, personajes que tienen un conflicto de índole moral y ético, y la lógica de Estado alrededor del funeral de Polinices.Por un lado, Antígona representa tal moralidad, por realizar un último homenaje a su hermano y, por el otro, Creonte representa la lógica de estado, que lo lleva a prohibir el entierro de un conciudadano que es considerado un traidor. La sacralidad, que en últimas es la forma como se representa el drama,desarrolla una visión en la que los personajes no son malos o buenos, sino que reaccionan ante las circunstancias, de modo que el conflicto se explica desde la figura de los fuertes y los débiles, desde los disidentes y los dictadores o de los ascendentes y los decadentes, características acompañadas de una intuición que está por encima de los límites de la conciencia. Su estilo musical se inscribe en el microtonalismo y su interés en tradiciones musicales no occidentales, como la ópera Noh japonesa (Leeuw, 1999).

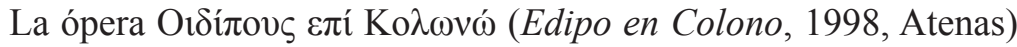
del compositor griego Theódoros Andoníu (1935) sigue en el libreto la versión de Sófocles de Mijailidis, donde la preponderancia no está en el destino, como en Edipo Rey, sino en la Justicia. La obra se concibió como 
una continuación del Oedipus Rex de Stravisnki, pero, según comenta el propio compositor, en un lenguaje diferente, intentando no dejarse influir por el compositor ruso en la medida de lo posible. En su obra, siguiendo a Stravisnki, utiliza en las partes cantadas griego clásico, una lengua rara y a la vez mágica, que, según Andoníu, simboliza una metápraxis o "transgresión" desde el punto de vista estético y musical (Andoníu, 1998).

También en la escena musical griega, Mikis Theodorakis (1925)

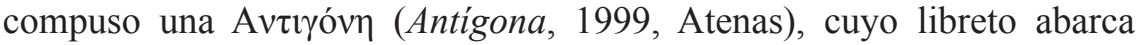
la totalidad del Ciclo Tebano. Para ello, se basó en las tragedias que se conservan sobre este mito en los tres grandes trágicos: Los Siete contra Tebas de Esquilo, La Fenicias de Eurípides y Edipo Rey y Antígona de Sófocles. La ópera cuenta con elementos balanceados de la tragedia y la lírica en los que la influencia de Verdi, Puccini y Bellini se encuentra presente (Theodorakis, 1999). El compositor ve en la saga tebana la dominación, la sed de poder y la autoridad, que se representa en Eteocles y Creonte; el acto trágico por excelencia está encarnado en la figura de Edipo; y en Yocasta se expresa la figura que sufre todo el peso de la tragedia al dar a luz hijos engendrados por su propio hijo. Estas lecturas de los dramas antiguos están influidas por los acontecimientos de la Segunda Guerra Mundial, que vivió Theodorakis, quien veía cómo este Ciclo Tebano se repetía de manera interminable en diferentes escenarios, como fue el caso de la Dictadura de los Coroneles en Grecia. Por otro lado, Antígona representa para el compositor, junto a Hemón, la esperanza, la inocencia en medio de la oscuridad, que a la vez son castigados y sacrificados injustamente; representan también que el bien no está muerto y que algún día vencerá y derrotará al instinto del mal por las fuerzas del amor y la belleza. La obra está compuesta en cinco actos en los que Theodorakis hace un himno poético en alabanza al amor trágico, alcanzando los límites de la expresión emocional más íntima y lírica (Theodorakis, 2004).

En el contexto de la experimentación de la música electrónica y el desarrollo de instrumentos electromecánicos,se encuentra la ópera Antigone (1999, Chicago) del compositor norteamericano John Eaton (1935). El libreto de Nicholas Rudall está basado en la obra homónima de Sófocles. Eaton, reconocido por sus composiciones e interpretaciones de música electrónica y microtonal, utilizó un espectro de notas por octava más amplio que el usual de doce tonos y se valió de instrumentos electrónicos para su composición, destacándose el uso del digital delay system, que da un efecto de eco sonoro. Eaton innovó en el género operístico con la 
llamada "pocket opera", consistente en obras compuestas para orquesta de cámara y un reparto reducido de voces (Albertson \& Hannah, 2017).

La última ópera del siglo es Antigone (2000, San Francisco) del compositor estadunidense Mark Alburger (1957). El libreto está basado en la adaptación moderna de la obra de Sófocles de Jean Anouilh, hecha durante la Segunda Guerra Mundial.De aquí que el dramaturgo francés haya hecho énfasis en la desobediencia civil durante la dominación nazi. Se trata de una ópera basada en Die Zauberföte de Mozart, de la que Alburger tomó la forma, pero poco del contenido musical. Según comenta el compositor, la música en su mayoría fue inspirada por el espíritu del personaje principal: el de la rebelión (Alburger, 2000). En esta línea, las claves mayores se vuelven menores, los tempi muy lentos se convierten en muy rápidos y los ritmos impasibles se hacen casi irracionalmente sincopados. Alburger señala asimismo que su composición también alude a las óperas Einstein on the Beach y Akhnaten de Glass, Amahl and the Night Visitors de Menotti, a la cantanta "Wachet Auf” de Bach, a la sinfonía No. 3 de Prokofiev, a la orquestación para la película Dances With Wolves de Barry, al ballet Pulcinella y al Ebony Concerto de Stravinski, entre otras obras y compositores, así como ritmos musicales, tales como la música griega antigua y las músicas rock y pop.

El siglo XXI abre con la ópera Antygona del compositor polaco Zbigniew Rudzinski (1935), estrenada en 2001 (Wroclaw). El libreto, adaptado por el propio compositor, sigue el texto de Sófocles, pero incluyendo como personajes a las Erinias que influyen en el comportamiento de los personajes. Con ello, Rudzinski busca despertar en el espectador compasión y angustia,haciendo a su vezénfasis enla expresión de emociones y sentimientos y las actuaciones de los personajes, que provocan resultados opuestos a los deseados, tal como él mismo declara: "En el drama de Sófocles me interesaron los problemas de la vida humana, los problemas de la felicidad, del sufrimiento, de la culpa, de las pasiones, del castigo y del destino; los problemas del orden del mundo y las leyes que rigen el destino del hombre ${ }^{10 "}$ (Rudziński, 2003, pp.11-12). La puesta en escena, a cargo de Marek Weiss-Grzesinski, se ambienta en una ciudad desolada por una guerra civil, que se encuentrabajo un régimen totalitario. Entre las ruinas, un grupo de antiterroristas encuentra el cuerpo de Polinices con barba

10 Agradecemos al Dr. Bogdan Piotrowski por su colaboración en la interpretación y traducción del texto original en polaco. 
negra y uniforme militar. La puesta en escena señala a los gobernantes que quieren justificar las atrocidades de la guerra y de una sociedad que acepta conforme tales decisiones. Solo unos pocos se rebelan, aunque, al final, el pueblo reconocerá en parte su heroísmo(Weiss-Grzesiński, 2003, p.15).

Otra orientación es la del compositor belga Pierre Bartholomée (1937) en su Oedipe sur la routede 2003 (Bruselas), cuyo libreto se basa en la novela del escritor y psicoanalista belga Henry Bauchau. El argumento de la novela se centra en los nexos entre la violencia y la sabiduría, la obsesión por la infancia, la pérdida de la figura materna y el rechazo del nacionalismo (Robin, 2004, p.5-6). La versión de Bauchau parte de las dos tragedias de Sófocles dedicadas a Edipo, situando la acción en la ruta que toman Antígona y su padre, y a la vez hermano, hacia Colono. Bartholomée comenta que le impactó de la novela de Bauchau "el movimiento secreto que anima la obra del gran escritor, la savia poética que la nutre, el pensamiento que la habita, las perspectivas que abre, la profunda introspección de la que procede y testimonia, las ideas que pone en juego, su consolidación en el sueño, su tono particular [...]" (Bartholomée, 2008a, p.210). Cuatro años más tarde, el compositor puso en escena La Lumière Antigone(Bruselas), una ópera basada en la otra novela de Bauchau que aborda el Ciclo Tebano: Antigone. En esta versión se narra el regreso de Antígona a Tebas, después de acompañar a su padre a Colono, su intención de evitar la guerra entre sus hermanos Polinices y Eteocles por el control de Tebas y su destino final. El cambio de título se debe a que Bartholomée vio en esta Antígona "una luz nueva, desconocida, frágil y violenta, insaciable, singular, una luz de obstinación [...]" en medio de la obscuridad, el silencio y la soledad de las personas que luchan y se enfrentan a decisiones inapelables (Bartholomée, 2008b, p. 220).

Volviendo al tema de los regímenes totalitaristas, Dominique Le Gendre (1960)estrenó la ópera The Burial At Thebes, en 2008 (Londres). La versión utilizada para el libreto es la traducción en verso del Premio Nobel irlandés Seamus Heaney de la Antígona de Sófocles. El lenguaje musical de la obra es un lenguaje propio que combina ritmos tradicionales de su natal Trinidad y Tobago. Un ejemplo de ello es el personaje de Creonte, cuyo carácter musical está basado en el ritmo rapso, una forma musical que combina el rap y el calipso, en el que el texto esel elemento más importante, lo que le proporciona al personaje de Creonte un rol dentro de la ópera principalmente rítmico. Esto simboliza la incapacidad de Creonte de entender que los asuntos estatales necesariamente afectan 
los personales. También enfatiza la brutalidad de su postura que es de alguna manera impersonal. Por otro lado, el ritmo flamenco caracteriza a Antígona, por la relación que hay con el 'compás' de doce golpes que se combinan en el ritmo y las voces. El resultado es un fuerte contraste entre los personajes: por un lado, profundamente lírico en el caso de Antígona e Ismene; por otro, excesivamente fuerte en Creonte. En la escenografía, se eligió como ambientación una isla que evoca la dictadura de Trujillo en República Dominicana(Le Gendre, 2012).

El compositor Carlos Stella (1961) compuso sus Antigonai (2009, Berlín) para la Berliner Cappella. El libreto se hizo con base en la traducción del poeta lírico Friedrich Hölderlin, con la influencia del escritor Walter Burkert (Stella, 2012a). En ella recrea el mito a partir de la influencia de varios compositores clásicos, como Bach, Purcell, Beethoven, Wagner y Verdi.Su obra es así un caleidoscopio de obras clásicas en un mito. La obra, según comenta Stella, está representada por tres coros: el primero esel coro femenino de 'Antígonas', que simboliza la conciencia trágicay que a través delíneas musicales expresansentimientos como los celos, la envidia, el amor y el recuerdo, es decir, la verdad. El segundo coro, llamado los 'Creontes' o 'coro de idiotas', es feliz y romántico y, al mismo tiempo, heroico y audaz, en medio de satisfacción, indiferencia, nobleza y apetito. El tercer coro representa el público, en el que se palpa todo el drama; trata de ser imparcial, aunque en últimas su actuación sea fría e imposible de alcanzar (Stella, 2012b).

Recientemente, el 3 de mayo del 2014 en la English National Opera se estrenó Thebans, la primera ópera del compositor Julian Anderson. El libreto estuvo a cargo de Frank Mc Guinness, quien realizó una adaptación del Ciclo Tebano de Sófocles: Edipo Rey, Edipo en Colono y Antígona. La intención del compositor y libretista fue reunir estas tres obras en una sola, de manera que la obra representara la vida de Edipo y su muerte, igual que Sófocles, pero proponiendoel siguiente desarrollo temporal: el primer acto representa el pasado, haciendo referencia a Edipo Rey; el segundo acto, el futuro, lo protagoniza Antígona; y, por último, el tercer acto, el presente, se basa en Edipo en Colono. La obra también profundiza en el trágico destino de la familia, en el que el presente (tercer acto) es determinante para explicar los conflictos de Edipo, por un lado, con sus hijos varones,en especial con Polinices, ya que lo aborrece y además prevé el desenlace final junto a su hermano, aunque pide a su hija que lo honre con un funeral; por otro lado, el encuentro con un Creonte tirano, que intenta forzar el 
regreso de Edipo a Tebas, agrediendo incluso, a Antígona para convencerle, aunque este es ahuyentado por Teseo que invoca a los dioses para que se marche. Finalmente, el último deseo de Edipo antes de morir en Atenas, de la mano de Teseo, es que su hija no lo vea morir ni que sepa el lugar; el llanto y el dolor de Antígona es el desenlace final de la obra (Anderson, 2014). En el aspecto musical, el compositor se detiene en las conexiones que hay entre la música y los eventos dramáticos en el escenario; es por eso que la armonía musical, compuesta por una diversidad de sonidos, acordes e intervalos, se sujeta al drama (Anderson, 2014).

Este mosaico de composiciones permite verla presencia del mito de los labdácidasen las distintas corrientes musicales occidentales, en tanto que encontramos óperas basadas en este mito desde el Verismo y el Neoclasicismo de principios de siglo XX, hasta las corrientes musicales contemporáneas de finales del siglo pasado y lo que va corrido del presente, pasando por las novedosas propuestas de la música electrónica, microtonal, el atonalismo, entre otras.

Los compositores siguen en su gran mayoría,la versión del mito que utilizó Sófocles en sus tres tragedias dedicadas a Edipo y a Antígona, tanto en las adaptaciones como en los textos íntegros. Para ello se basaron en las traducciones ampliamente conocidas de Hölderlin, Yeats, Mijailidis, Sheaney, etc. Las excepciones son Mikis Theodorakis, quien conjuga los dramas griegos antiguos sobre el ciclo tebano en un libreto propio que tiene como base la Antígona de Sófocles; Josep Soler, quien siguió la versión de Séneca; y Julian Anderson, quien condensó las tragedias de Sófocles dedicadas a dicho ciclo. La preferencia del tragediógrafo ateniense se debe a que es mucho más conocida la versión griega. Sin embargo, es necesario tener en cuenta que, entre las distintas versiones del mito, hay notables diferencias en el tratamiento de los personajes. El Edipo de Séneca, por ejemplo, es un personaje atormentado y aterrador, dominado por el sentimiento de culpa y por la sospecha, mientras que el carácter del personaje de Sófocles es orgulloso y voluble. Esto corresponde a necesidades estilísticas e ideológicas, ya que Josep Soler se centra en un aspecto ético y moral de la música, con lo que encuentra en la versión de Séneca un impacto mayor sobre el público, a través de la fijación en el páthos y la violencia, así como la presencia de escenas truculentas, que tanto agradaban al público romano, como la descripción del sacrificio de Tiresias. Igualmente significativas son los libretos basados en novelas u obras de teatro que reelaboran el mito de los labdácidas en nuevos 
contextos, como en el caso de Berkoff, quien transforma la figura de Edipo en un 'emprendedor' que proviene de clase obrera; o el de Bauchau, quien se interesa por los sucesos del drama de Edipo y Antígona no contados por Sófocles en búsqueda de una introspección psicoanalítica de dichos personajes.

De los personajes que conforman el Ciclo Tebano,solo a dos de ellos se han dedicado óperas, debido a que son los personajes míticos más conocidos; a diferencia de lo que sucedía en la Antigüedad,cuando otros personajes despertaban también interés, debido a que se conocían mejor los mitos y las obras que trataban de ellos. No obstante, es, en los albores del siglo XX, la asociaciónhecha por Freud delos intrincados y oscuros laberintos del inconsciente humano con la figura de Edipo, la que hace renacer el mito como un símbolo de los deseos y ansiedades ocultos delhombre moderno, que siente cómo se perturba su mente ante la posibilidad de compartir ese mismo destino; sumado ala figura de un ser que no puede escapar de su destino y comete sin saber los más atroces crímenes, y que,por su carácter arrogante e impulsivo, se convierte irónicamente en el más implacable investigador de sus propios crímenes, que al final también se convierte en juez para aplicar sobre sí mismo la más dura sentencia. Este interés por Edipo naturalmente se traslada a Antígona, en la que se ve una disputa entre el poder del estado y los derechos civiles, lectura claramente influida por la inestabilidad política de los períodos de entreguerras y los regímenes totalitaristas. Antígona es, en esta perspectiva, una heroína cuya determinación la lleva a cuestionar, retar y transgredir las decisiones del Tirano para hacer respetar derechos que están más allá del poder que puede ejercer el estado.

Por último, podemos esperar que el mito seguirá nutriendo la escena musical operística durante el siglo XXI, pues los compositores contemporáneos siguen encontrando en él, y otros tantos, una fuente de inspiración, de modo que se asegura su interpretación y transmisión por esta vía artística, ya quela Ópera seguirá siendo un escenario propicio para ello, pues en ella hay un punto de encuentro de todas las artes y de todas las épocas.Por otra parte, cada composición, cada puesta en escena y cada recreación de los mitos sumerge al espectador en el eterno oleaje del tiempo, donde se mezclan presente y pasado, innovación y tradición, realidad y ficción, y en el que seguirán a la deriva los descendientes de Lábdaco para fascinar y conmover el espíritu humano por el infausto destino de un linaje condenado a permanecer en la memoria de los siglos. 


\section{Listado de óperas}

\begin{tabular}{|c|c|c|c|}
\hline Fecha & Título & Compositor & Libreto \\
\hline 1919 & Edipo re & R. Leoncavallo & G. Forzano (Sófocles) \\
\hline 1927 & Oedipus Rex & I. Stravinski & J. Cocteau (Sófocles) \\
\hline 1927 & Antigone & A. Honegger & $\begin{array}{l}\text { A. Honegger (Coctaeu, } \\
\text { Sófocles) }\end{array}$ \\
\hline 1936 & Oedipe & G. Enescu & E. Fleg (Sófocles) \\
\hline 1949 & Antígona & C. Orff & F. Hölderlin (Sófocles) \\
\hline 1959 & $\begin{array}{l}\text { Oedipus der } \\
\text { Tyrann }\end{array}$ & “ & “ \\
\hline $\begin{array}{l}1650- \\
1967\end{array}$ & Oedipus & H. Partch & W. Yeats (Sófocles) \\
\hline 1963 & Antigona '43 & L. Pipkov & $\begin{array}{l}\text { V. Bashev y P. Panchev } \\
\text { (Sófocles) }\end{array}$ \\
\hline 1968 & $\begin{array}{c}\text { The Passion of } \\
\text { Oedipus }\end{array}$ & R. Travis & R. Travis (Sófocles) \\
\hline 1973 & Antigonae & M. Kupferman & $\begin{array}{l}\text { M. Kupferman (Hölderlin, } \\
\text { Sófocles) }\end{array}$ \\
\hline 1971 & $\begin{array}{l}\text { Death of } \\
\text { Antigone }\end{array}$ & R. Smith Brindle & $\begin{array}{c}\text { R. Smith Brindle (Sófocles, } \\
\text { Eurípides) }\end{array}$ \\
\hline 1986 & $\begin{array}{l}\text { Oedipus et } \\
\text { Iocasta }\end{array}$ & J. Soler & J. Soler (Séneca, Sófocles) \\
\hline 1988 & Greek & M.A. Turnage & $\begin{array}{l}\text { M.A. Turnage y J. Moore } \\
\text { (Berkoff) }\end{array}$ \\
\hline 1991 & $\begin{array}{l}\text { Antígona } \\
\text { Furiosa }\end{array}$ & J. M. Liderman & A. Feder (Gambaro) \\
\hline 1993 & Antigone & T. de Leeuw & T.de Leeuw (Sófocles) \\
\hline 1997 & 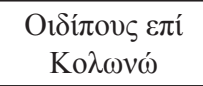 & Th. Andoníu & G. A. Michailidis (Sófocles) \\
\hline 1999 & 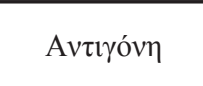 & M. Theodorakis & $\begin{array}{l}\text { M. Theodorakis (Esquilo, } \\
\text { Sófocles, Eurípides) }\end{array}$ \\
\hline 1999 & Antigone & J. Ch. Eaton & N. Rudall (Sófocles) \\
\hline 2000 & Antigone & M. Alburger & J. Anouilh (Sófocles) \\
\hline 2001 & Antygona & Z. Rudzinski & Z. Rudzinski (Sófocles) \\
\hline 2003 & $\begin{array}{l}\text { Edipe sur la } \\
\text { route }\end{array}$ & P. Bartholomée & $\begin{array}{c}\text { Pierre Bartholomée (Bauchau, } \\
\text { Sófocles) }\end{array}$ \\
\hline
\end{tabular}




\begin{tabular}{|c|c|c|c|}
\hline 2007 & $\begin{array}{c}\text { La Lumière } \\
\text { Antigone }\end{array}$ & “ & “ \\
\hline 2008 & $\begin{array}{c}\text { The Burial At } \\
\text { Thebes }\end{array}$ & D. Le Gendre & S. Heaney (Sófocles) \\
\hline 2009 & Antigonai & C. Stella & $\begin{array}{c}\text { C. Stella (Hölderlin, Burkert, } \\
\text { Sófocles) }\end{array}$ \\
\hline 2014 & Thebans & J. Anderson & F. Mc Guinness (Sófocles) \\
\hline
\end{tabular}

\section{REFERENCIAS BIBLIOGRÁFICAS}

ALBERTSON, D., \& HANNAH, R. (2017). The Living Composers Project: Jon Eaton. Obtenido de http://composers21.com/compdocs/eatonj.htm

ALBURGER, M. (2000). Mark Alburger, Works. Obtenido de Antigone, Op. 88: http://markalburgerworks.blogspot.com.es/2000/08/antigone-op-88.html ANDERSON, J. (2014). Imagining Ambiguity - A composer's thoughts on setting Thebans. London: English National Opera.

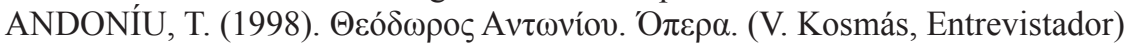

To Bท́ $\mu \alpha$. Obtenido de http://www.tovima.gr/relatedarticles/ article/?aid $=99004$

BARTHOLOMÉE, P. (2008a). Du roman à l'opéra: CEdipe sur la route. En: R. WANGERMÉE (Ed.), Pierre Bartholomée: parcours d'un musicien (pp. 210-219). Wavre: Mardaga.

--------, (2008b). Antigone ou la mort traversée. En R. WANGERMÉE (Ed.), Pierre Bartholomée: parcours d'un musicien (pp. 220-223).

Wavre: Mardaga.

BERNOFSKY, S. (2001). "Hölderlin as Translator: The Perils of Interpretation", The Germanic Review: Literature, Culture, Theory, 76, 215-233.

BETA, S. (2002). "Dalla scena tragica al palcoscenico lirico: l'Edipo Re di Giovacchino Forzano e Ruggero Leoncavallo", Kleos: estemporaneo di studi e testi sulla fortuna dell'antico, 7, 31-54.

BETTINI, M., \& GUIDORIZZI, G. (2008). El mito de Edipo. Imágenes y relatos de Grecia a nuestros días (M. A. Castiñeiros González, Trad.). Madrid: Akal.

BLACKBURN, P. (1998). Enclosure five: Harry Partch. Minnesota: Innova Recordings.

BOSI, K. (2003). "Accolades for an Actress: On Some Literary and Musical Tributes for Isabella Andreini”, Recercare. Rivista per lo studio e la pratica della musica antica, 15, 73-117. 
BROWN, P. (2004). Greek Tragedy in the Opera House and Concert Hall of theLate Twentieth Century. En: E. HALL, F. MACINTOSH, \& A. WRIGLEY (Eds.), Dionysus Since 69: Greek Tragedy at the Dawn of the Third Millennium(pp. 285-308). Oxford: Oxford University Press.

BRUACH MENCHÉN, A. (2010). La música escénica y el significado ético de la creación artística. En: J. CUSCÓ I CLARASÓ (Ed.), Josep Soler $i$ Sardà. Componer y vivir (pp. 123-142). Zaragoza: Libros del Innombrable.

CAMINO, F. (2001). Ópera. Madrid: Ollero \& Ramos.

CLUBB, L. G. (2001). Italian Renaissance Theatre. En: J. R. BROWN (Ed.), The Oxford Illustrated History of Theatre (pp. 107-41). Oxford: Oxford Universtiy Press.

COTELLO, B. (2001). Oedipe. Obtenido de http://www.oedipe.org/es/spectacle/ oedipe-opera

DANA, C. (2017). University of California Academic Senate. Obtenido de http://senate.universityofcalifornia.edu/_files/inmemoriam/html/ jorgemarioliderman.html

EWANS, M. (2007). Opera from the Greek: Studies in the Poetics of Appropriation. Aldershot: Ashgate.

FENLON, I. (2008). Music and Patronage in Sixteenth-Century Mantua (Volume 2, Cambridge Studies in Music). Cambridge: Cambridge University Press.

FLASHAR, H. (1991). Inszenierung der Antike. Das griechische Drama auf der Bühne der Neuzeit. München: C. H. Beck.

FULCHER, J. F. (2006). French Identity in Flux: The Triumph of "Antigone", Journal of Interdisciplinary History, 36 (4),649-674.

GIDI BLANCHET, C. (2016). "El heroísmo en los tiempos actuales: Antígona furiosa de Griselda Gambaro y Usted está aqui de Bárbara Colio", Valenciana, 18, 187-214.

GRAB, F. D. (1972). "Yeats's "King Oedipus"”, The Journal of English and Germanic Philology, 71(3), 336-354.

KAMINSKI, P. (2003). Millet et un opéras. París: Fayard.

KUPFERMAN, M. (2010). Meyer Kupferman. American Composer (19262003). Obtenido de http://www.meyerkupferman.com/html/works.php

LE GENDRE, D. (2012). The Burial At Thebes. (L. M. Forero, Entrevistador).

LEEUW, T. de. (1999). Antigone [Grabado por U. C. Netherlands Radio Chamber Orchestra]. Amsterdan: Nm Classics.

MECHELLI, P. (2011). La scena di prigione nell 'opera italiana fra Settecento e Ottocento. Munich: Grin.

OYARZÚN, P. (2001). "Friedrich Hölderlin. Anotaciones al Edipo. Anotaciones a la Antígona. Noticia, traducción y notas", Revista teoría del arte, 4, 79-115. 
READ, G. (1998). Pictographic Score Notation: A Compendium. Westport: Greenwood Press.

RICHTER, M. (2005). Opera from Bulgaria. Obtenido de http://www.ucis.pitt. edu/opera/BULGOP/comp/pipkov.htm

ROBIN, B. (2004). Pour lire CEdipe sur la route d'Henry Bauchau. Obtenido de Service du Livre Luxembourgeois: http://www.servicedulivre.be/servlet/ Repository/Pour_lire_PDF?IDR=5309

ROSS GRIFFEL, M. (2013). Operas in English: A Dictionary. Plymouth: Scarecrow.

RUDZIŃSKI, Z. (2003). Opera to Śpiew. En B. SMOLIŃSKA-PELCZAR (Ed.), Zbigiew Rudziński. Antygona (págs. 10-12). Wroclaw: Opera Dolnośląska.

STELLA, C. (2012a). Antigonai. (L. M. Álvarez, Entrevistador). , (2012b). Ideas recurrentes. (L. M. Álvarez, Entrevistador).

THEODORAKIS, M. (1999). Antigone [Grabado por N. O. Athens State Orchestra]. Atenas: FM Records.

(2004). Theodorakis. Obtenido de http://en.mikis-theodorakis.net/index.php/article/articleview/286/1/49/

USCATESCU, J. (1980). "Hölderlin y la esencia de lo trágico",Cuadernos de la Fundación Pastor, 25, 39-64.

WALSH, S. (1993). Stravinsky: Oedipus Rex. Cambridge: Cambridge Music Handbooks.

WEISS-GRZESIŃSKI, M. (2003). Antygona. Streszczenie spektaklu. En: B. SMOLIŃSKA-PELCZAR (Ed.), Zbigiew Rudziński. Antygona (pp. 1415). Wroclaw: Opera Dolnośląska.

WERNER, T. (1991). Orff. En: Pipers Enzyklopädie des Musiktheaters (Band 4, pp. 581ss). München: Piper.

YEATS, W. B. (1928). Sophocles' King Oedipus (Translation).New York: Macmillan. 